ScIDice

\section{Working Length Of Maxillary Primary Second Molars In Children Aged 2-6 Years - A Retrospective Study}

International Journal of Dentistry and Oral Science (IJDOS) ISSN: $2377-8075$

Research Article

Sruthi $\mathrm{S}^{1}$, Deepa Gurunathan ${ }^{2 *}$

${ }^{1}$ Saveetha Dental College Saveetha Institute of Medical and Technical Sciences Saveetha university Chennai, India.

${ }^{2}$ Professor, Department of Pedodontics, Saveetha Dental College Saveetha Institute of Medical and Technical Sciences Saveetha University Chennai, India.

\title{
Abstract
}

\begin{abstract}
Aim: The predictable endodontic success demands an accurate working length. Thus, the aim of the study is to compare the working length of each root canal obtained for primary maxillary second molars in children aged 2-6 years.

Materials and Methods: A retrospective study was carried out using digital records of 1,372 children who reported to the Department of Paediatric and Preventive Dentistry from June 2019 to March 2020. A total of 113 records that mentioned maxillary primary second molars $(55,65)$ were finally included for the study evaluation. Patients between the age group of 2-6 years were included in the study. The following data were retrieved from the dental records: age, gender, working length of each canal and pulpal pathology. The records were examined and noted in a spreadsheet. The collected data was analysed by computer software SPSS version 21 using one-way Anova test with the level of significance set at $5 \%$.

Results: The mean age was observed to be 4.66 years in the present study. Gender showed an unequal distribution of participants. The mean working length of the root canal in each canal is more when the patient has only pain when compared with other pathology such as swelling, Abscess, Resorption. One way ANOVA test, $\mathrm{p}$ value $=0.00(<0.05)$ Hence, statistically significant.

Conclusion: The mean working length was found to be $10.82 \mathrm{~mm}$ (MB canal), 10.72mm (DB canal), 12.80mm (Palatal canal) with respect to pulpal pathology $(\mathrm{P}=0.00)$. The reported data may help clinicians to obtain a thorough understanding on the working length of primary maxillary second molars.

Clinical Significance: The purpose of this study was to evaluate the mean working length of MB canal, DB canal and Palatal canal in primary maxillary second molars and to compare the results with pulp pathology such as pain, swelling, abscess and resorption.
\end{abstract}

Keywords: Root Canal; Maxillary Second Molars; Primary Teeth; Working Length.

\section{Introduction}

In paediatric dentistry, the utmost important concern is the loss of necrotic primary molar teeth leading to space loss [1]. Pulpectomy is the preference of choice for managing symptomatic decayed primary teeth and is a demanding and time-consuming procedure [2-5]. An efficient chemomechanical preparation is fundamental for effective canal disinfection and by that contributes to the accomplishment of the endodontic procedure $[2,6,7]$. Conservation of a primary tooth whose pulp has been endangered is a unique challenge to the paediatric dentist in caring for the teeth of children. The major barrier in conveying appropriate dental care by the dentist during this situation and the dentist fear of any further risk to a permanent successor [8]. Moreover, morphological structure of the root canals in deciduous teeth make mechanical debridement and subsequent filling difficult. The objective in pup therapy by the paediatric dentist has always been the same, i.e., to preserve the tooth in a non-pathologic, healthy condition, perform its role in mastication and also serve as an excellent space maintainer for the permanent dentition. In addition, the circumstance of comfort, speech and interception of aberrant habits can be best guarded by retention of the primary tooth in the dental

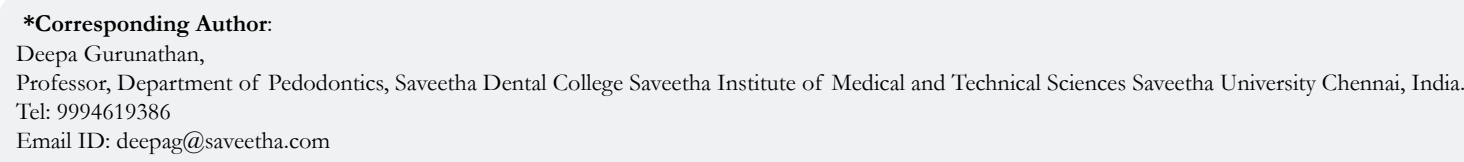

Copyright: Deepa Gurunathan 2021 . This is an open-access article distributed under the terms of the Creative Commons Attribution License, which permits unrestricted use, distribution and reproduction in any medium, provided the original author and source are credited. 
arch.

Before beginning pulpectomy, the clinician should perceive the morphologic changes that constantly exist within primary teeth and be familiar with the key characteristics between primary and permanent root canal anatomy. The maxillary deciduous molars may have two to five canals, with the palatal root generally rounder and longer than the two facial roots. In the mesiofacial root, two canals occur in approximately $75 \%$ of the primary maxillary first molars and $85-95 \%$ of primary maxillary second molars [9]. The success of a pulpectomy procedure mainly depends on definite determination of the root canal length. The procedure for establishment of working length should be performed with skill, using techniques that have been confirmed to give valuable and accurate results and by techniques that are simple and effective. A working length established farther the apical foramen may lead to apical perforation and overfilling. Alternatively, a working length established short of the apical foramen may lead to inadequate debridement and under filling. Retained pulp tissue may remain and cause prolonged pain. Several techniques have been suggested to determine root canal length, but the ideal procedure is yet to be identified.

There are numerous techniques for determining the working length (Radiographic, Apex locators, Tactile), but none of these are impeccable. The radiographic technique is the most accepted method (and remains so) of measuring working length in root canal therapy. It is simple but also has certain limitations like radiation exposure, in most cases the dentinocemental junction (DC). Junction does not concur with the radiographic apex and it gives a two-dimensional image and simply contribute reliable information on the location of the radiographic apex [10]. Considering, that the apical foramen generally does not coincide with the radiological apex, locating the file at the radiological apex will often drive to over instrumentation. Digital radiographic method is the novel and promising method of measuring working length. The advantages of RVG over conventional radiographs are the acceleration of image acquisition, diminished patient radiation dosage and the circumstance of image editing [11]. Use of radiography to forecast root canal length may not always lead to accurate results notably in case of physiological resorption of primary teeth. Instrumentation and/or overfilling becomes much more probable if there is a mistake in measurement technique, thus the germ of a permanent tooth might get injured [12-14]. Moreover, poor cooperation of children makes it onerous to take a radiograph with sufficient diagnostic value [15].

There are only a small number of known studies on working length determination of maxillary second molars in deciduous teeth. To our knowledge, no previous studies have investigated the working length of each canal with respect to pulpal pathology. Therefore, the present study was focused on working length determination with respect to pulpal pathosis such as pain, swelling, abscess and resorption in maxillary primary second molar teeth in children aged 2-6 years.

\section{Materials and Method}

\section{Study Design}

This retrospective study was conducted in the Department of
Pediatric and Preventive Dentistry in a Dental College in Chennai. Data from 1,372 pulpectomy treated teeth were collected from dental records. Data were collected from the month of June 2019 to March 2020. At data extraction, all information was anonymized and tabulated onto a spreadsheet. The study was commenced after approval from the Institutional Scientific Review Board, Saveetha Dental College and Hospitals.

To fulfil the inclusion criteria, patients between the age group of 2-6 years in teeth with extensive caries, presence of two-third of root length and evidence of pulpal pathology such as pain, swelling, abscess and resorption were considered for the present study. Teeth that are non-restorable were excluded from the study.

Out of 1,372 records that were retrieved, 1,259 records were excluded as they were records of other primary teeth that are not required for the study. A total of 113 records which consisted of primary maxillary second molars $(55,65)$ were finally included for the study evaluation. The following data were retrieved from the dental records: age, gender, working length of each root canal and pulpal pathology. The records were examined and noted in a spreadsheet.

\section{Statistical Analysis}

The statistical analysis was done using SPSS software version 21.0 (SPSS Inc., Chicago, IL, USA). One way Anova test was used to compare the working length between the three root canals. The significance level was set at $5 \%$ for the present study.

\section{Results}

In this study, out of 113 records the mean age was observed to be 4.66 years. Gender showed an unequal distribution of participants [Figure-1]. The mean working length was found to be $10.82 \mathrm{~mm}$ (MB canal), $10.72 \mathrm{~mm}$ (DB canal), $12.80 \mathrm{~mm}$ (Palatal canal) with respect to pulpal pathology [Table-1, Figure-2,3,4]. One way Anova test between the three root canals showed a statistically significant difference in the mean working length $(\mathrm{P}=0.00)$ [Table-1].

\section{Discussion}

Oral health plays an important role in the general well-being of individuals, and parents' behavior and attitudes influence the oral health of their children [16]. Dental caries is a complex process of demineralization and dissolution of the substance of the teeth leading to cavitation $[17,18]$. It is a comprehensive oral health dispute with distinctive divergence in its distribution. It continues to be the most prevalent infectious disease in the children [19]. To establish correct tooth spacing, mastication, phonation, esthetics and interception of psychological effects due to tooth loss, preservation of pediatric dental integrity is important [20].

Fluoride is one of the direct ways in decreasing the prevalence of caries and its progression. It has been recommended for more than 50 years to prevent and control dental caries and it is a naturally occurring substance which is present in water [21, 22]. Ranula is a cystic lesion that appears in the floor of the mouth. It can interfere with the endodontic management [23]. Hence it should be surgically removed to gain proper access. In young children, the frenum is generally wide and thick which becomes thin and 
Figure 1. Bar chart showing the frequency distribution of participants. X-axis shows the number of participants. Y-axis shows ender who are children labelled as male and female. Bar chart shows an unequal distribution of participants.

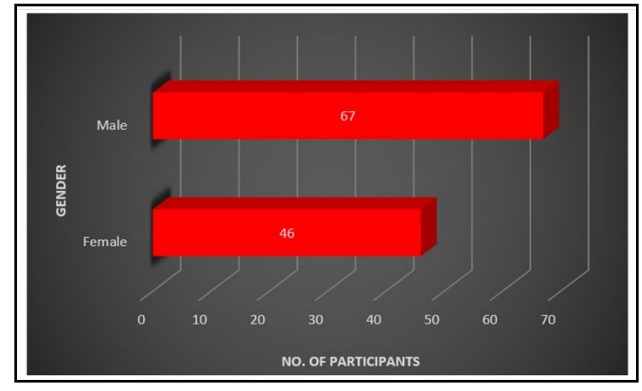

Figure 2. Bar chart showing distribution of MB canal length $(55,65)$ in respect to pulp pathology where blue colour denotes pain, red denotes swelling, green denotes abscess and orange denotes resorption. $\mathrm{X}$-axis shows the working length of root canals in $\mathrm{mm}$. Y-axis shows the number of MB root canals on a scale of 0-50 (count). The mean working length of root canal in MB canal is more when patient has only pain $(10.90 \mathrm{~mm})$ when compared with other pathology such as swelling $(10.77 \mathrm{~mm})$, Abscess $(10.32 \mathrm{~mm})$, Resorption $(10.06 \mathrm{~mm})$. One way ANOVA test, p value- $0.00(<0.05)$ Hence, statistically significant.

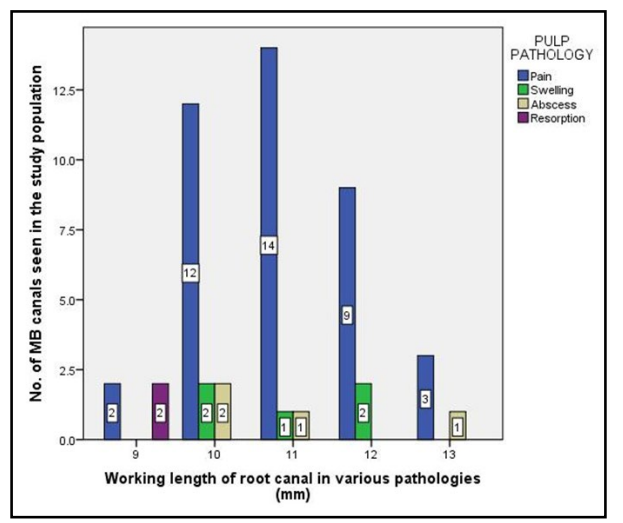

Figure 3. Bar chart showing distribution of DB canal length $(55,65)$ in respect to pulp pathology where blue colour denotes pain, red denotes swelling, green denotes abscess and orange denotes resorption. $\mathrm{X}$-axis shows the working length of root canals in $\mathrm{mm}$. Y-axis shows the number of DB root canals on a scale of 0-50 (count). The mean working length of root canal in DB canal is more when patient has only pain $(10.8 \mathrm{~mm})$ when compared with other pathology such as Swelling $(10.64 \mathrm{~mm})$, Abscess $(10.24 \mathrm{~mm})$, Resorption $(10.01 \mathrm{~mm})$. One way ANOVA test, p value $-0.00(<0.05)$ Hence statistically significant.

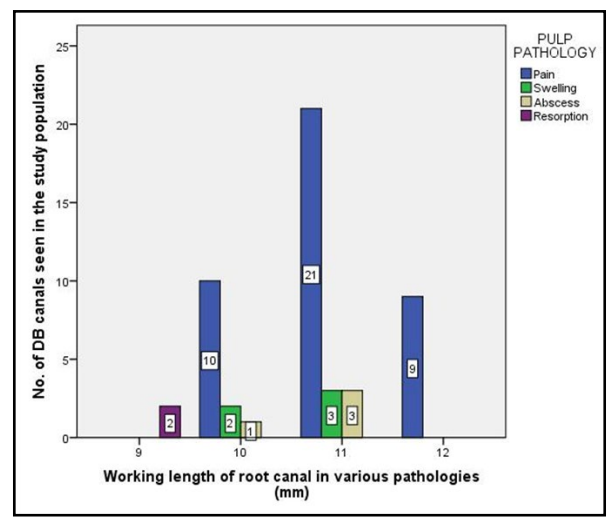

small during growth. Thick frenum makes cleaning in that area difficult causing plaque accumulation which in turn may lead to caries in primary teeth [24].

The main objective of pulpectomy for deciduous teeth is to debride the root canals of infected teeth [25], hence, precise insight of the root and root canal morphology of deciduous teeth can markedly improve the effectiveness and outcome of treatment. It is commonly established that canal preparation and filling should be finite within the root canal [26]. Hence, accurate working length during pulpectomy of primary teeth is necessary to promote complete cleaning and disinfection of the root canals as well as to avoid damage to the permanent tooth germ [27]. Haulk et al and Katz et al performed study to determine working length in dry and wet environment and found no statistically significant difference in both the canal condition [28]. Also number of in vivo and in vitro comparative studies have performed to evaluate accuracy of apex locators with radiographic, tactile sense, visual method and digital radiographic method. No significant difference was found between the methods compared [29-31].

Conventional radiography as a technique of determining the 
Figure 4. Bar chart showing distribution of palatal canal length $(55,65)$ in respect to pulp pathology where blue colour denotes pain, red denotes swelling, green denotes abscess and orange denotes resorption. $\mathrm{X}$-axis shows the working length of root canals in $\mathrm{mm}$. Y-axis shows the number of palatal root canals on a scale of 0-30 (count).The mean working length of root canal in palatal canal is more when the patient has only pain $(12.74 \mathrm{~mm})$ when compared with other pathology such as swelling $(12.58 \mathrm{~mm})$, Abscess $(12.34 \mathrm{~mm})$, Resorption $(11.89 \mathrm{~mm})$. One way ANOVA test, p value $-0.000(<0.05)$ Hence statistically significant.

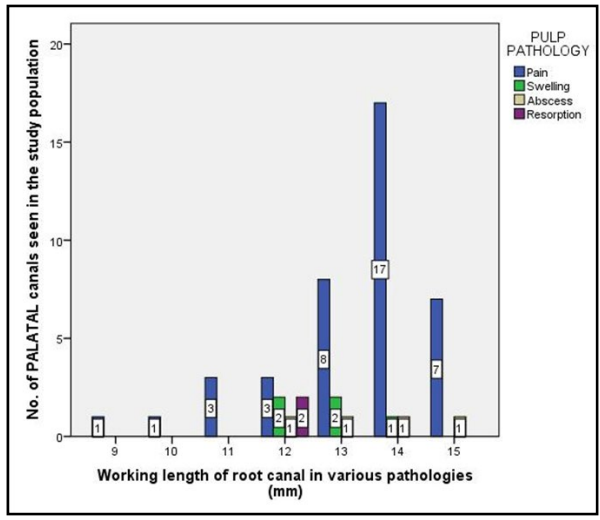

Table 1. Comparison of working length between the three root canals.

\begin{tabular}{|c|c|c|}
\hline $\begin{array}{c}\text { Working length } \\
(\mathbf{n}=\mathbf{1 1 3})\end{array}$ & Mean $\mathbf{\pm}$ SD & $\begin{array}{c}\text { Overall } \\
\text { p-value }\end{array}$ \\
\hline MB canal & $10.85 \pm 0.95$ & \multirow{2}{*}{$\mathrm{P}=0.00$} \\
\hline DB canal & $10.82 \pm 0.83$ & \\
\hline PALATAL canal & $12.79 \pm 1.58$ & \\
\hline
\end{tabular}

*One way ANOVA test, $\mathrm{p}$ value obtained $(\mathrm{p}<0.05)$

working length has diverse shortcomings in that it depends on the child's cooperation, along with the operator's proficiency. In addition to this, minor degrees of resorption may not be noticeable, and overlapping by neighboring anatomical structures can obscure the clarity of the image [32]. The other crucial dispute associated with intra oral periapical radiograph is the positioning of the film inside the mouth [29] and the need of developing, fixing, drying and storage of the film. The above problems associated with conventional radiographs were overcome with the launch of intra oral digital radiography. It grants immediate display of image, image enhancement, storage, retrieval and transmission. Other advantages consist of ease of repetition and the withdrawal of chemical usage. It also lessens the need for a dark room, films, mounts and processing equipment [33]. The radiovisiography images develop instantly on the monitor screen after exposure of the sensor image; and can be used for patient education directly. Reduced exposure time allows lower radiation dosage and reduces chair side time. Researches have shown that intra oral digital radiograph can be safely used in measurements of root length in root canal treatment.

According to Bagherian, A et al, palatal root canal showed maximum root length, with a mean of $9.92 \mathrm{~mm}$ and DB root showed the minimum length with a mean of $7.21 \mathrm{~mm}$. This study has compared the root length whereas, working length in respect to each canal was not mentioned. The present study has compared the mean working length of each canal with respect to pulp pathology, which is not found in the literature. The mean working length of root canal with pathology were observed in case of pain (MB10.90, DB-10.8mm, Palatal-12.74mm), Swelling (MB-10.77mm, DB- 10.64mm, Palatal-12.58mm), Abscess (MB-10.32mm, DB- 10.24mm, Palatal- 12.34mm), Resorption (MB- 10.06mm, DB$10.01 \mathrm{~mm}$, Palatal- $11.89 \mathrm{~mm}$ ). During pain, swelling, abscess and resorption, palatal canal was observed to have maximum working length, whereas DB canal was found to have minimum working length. The existence of root resorption is an important characteristic of pulpectomy in primary teeth. It is hard to radiologically assess the small areas of resorption especially if the resorption is on the buccal or lingual aspects of the root.

No comparison with other groups such as tactile method, conventional radiograph, apex locators has been used in the present study. Only digital radiographs were used by the dentists for determining the working length of primary maxillary second molars. This is a potential source of bias. In the future, large sample size with all parameters such as root canal morphology, root angulation, root length should be studied in detail.

\section{Conclusion}

The working length differs according to each pathology such as pain, swelling, abscess and resorption. The mean working length in the current study was observed to be $10.82 \mathrm{~mm}$ (MB canal), $10.72 \mathrm{~mm}$ (DB canal), $12.80 \mathrm{~mm}$ (Palatal canal) with respect to pulpal pathology. The reported data may help clinicians to obtain a thorough understanding on the working length of primary maxillary second molars.

\section{Clinical Significance}

The purpose of this study was to evaluate the mean working length of MB canal, DB canal and Palatal canal in primary maxil- 
lary second molars and to compare the results with pulp pathology such as pain, swelling, abscess and resorption.

\section{Acknowledgement}

I would like to acknowledge everyone who has provided patient advice and guidance through the research process. Thank you all for your unwavering support.

\section{References}

[1]. Jeevanandan G. Kedo-S Paediatric Rotary Files for Root Canal Preparation in Primary Teeth - Case Report. J Clin Diagn Res. 2017 Mar; 11(3): ZR03ZR05. PMID: 28511532.

[2]. Govindaraju L, Jeevanandan G, Subramanian EMG. Comparison of quality of obturation and instrumentation time using hand files and two rotary file systems in primary molars: A single-blinded randomized controlled trial. Eur J Dent. 2017 Jul-Sep; 11(3): 376-379. PMID: 28932150.

[3]. Panchal V, Jeevanandan G, Subramanian E. Comparison of instrumentation time and obturation quality between hand K-file, $\mathrm{H}$-files, and rotary Kedo-S in root canal treatment of primary teeth: A randomized controlled trial. J Indian Soc Pedod Prev Dent. 2019 Jan-Mar; 37(1): 75-79. PMID: 30804311.

[4]. Jeevanandan G, Govindaraju L. Clinical comparison of Kedo-S paediatric rotary files vs manual instrumentation for root canal preparation in primary molars: a double blinded randomised clinical trial. Eur Arch Paediatr Dent. 2018 Aug; 19(4): 273-278. PMID: 30003514

[5]. Nair M, Jeevanandan G, Vignesh R, Subramanian EM. Comparative evaluation of post-operative pain after pulpectomy with $\mathrm{k}$-files, kedo-s files and mtwo files in deciduous molars-a randomized clinical trial. Brazilian Dental Science. 2018 Oct 24; 21(4): 411-7.

[6]. Govindaraju L, Jeevanandan G, Subramanian EM. Knowledge and practice of rotary instrumentation in primary teeth among indian dentists: A questionnaire survey. Journal of International Oral Health. 2017 Mar 1; 9(2): 45.

[7]. Govindaraju L, Jeevanandan G, Subramanian E. Clinical Evaluation of Quality of Obturation and Instrumentation Time using Two Modified Rotary File Systems with Manual Instrumentation in Primary Teeth. J Clin Diagn Res. 2017 Sep; 11(9): ZC55-ZC58. PMID: 29207834.

[8]. Ravikumar D, Jeevanandan G, Subramanian EMG. Evaluation of knowledge among general dentists in treatment of traumatic injuries in primary teeth: A cross-sectional questionnaire study. Eur J Dent. 2017 Apr-Jun; 11(2): 232-237. PMID: 28729799.

[9]. Hess W, Zürcher E. The anatomy of the root-canals of the teeth of the permanent dentition. J. Bale, sons \& Danielsson, Limited; 1925.

[10]. Martínez-Lozano MA, Forner-Navarro L, Sánchez-Cortés JL, Llena-Puy C. Methodological considerations in the determination of working length. Int Endod J. 2001 Jul; 34(5): 371-6. PMID: 11482720.

[11]. Ellingsen MA, Hollender LG, Harrington GW. Radiovisiography versus conventional radiography for detection of small instruments in endodontic length determination. II. In vivo evaluation. J Endod. 1995 Oct; 21(10): 516-20. PMID: 8596074.

[12]. Bahrololoomi Z, Soleymani AA, Modaresi J, Imanian M, Lotfian M. Accuracy of an Electronic Apex Locator for Working Length Determination in Primary Anterior Teeth. J Dent (Tehran). 2015 Apr; 12(4): 243-8. PMID: 26622278

[13]. Jerrell RG, Ronk SL. Developmental arrest of a succedaneous tooth following pulpectomy in a primary tooth. J Pedod. 1982 Summer; 6(4): 337-42. PMID: 6957588.
[14]. Ahmed HM. Anatomical challenges, electronic working length determination and current developments in root canal preparation of primary molar teeth. Int Endod J. 2013 Nov; 46(11): 1011-22. PMID: 23711096.

[15]. Oznurhan F, Ünal M, Kapdan A, Ozturk C, Aksoy S. Clinical evaluation of apex locator and radiography in primary teeth. Int J Paediatr Dent. 2015 May; 25(3): 199-203. PMID: 25073636.

[16]. Gurunathan D, Shanmugaavel AK. Dental neglect among children in Chennai. J Indian Soc Pedod Prev Dent. 2016 Oct-Dec; 34(4): 364-9. PMID: 27681401.

[17]. Balsaraf S, Chole R. Epidemiology of dental caries - A review. Universal Research Journal of Dentistry. 2016; 206.

[18]. Subramanyam D, Gurunathan D, Gaayathri R, Vishnu Priya V. Comparative evaluation of salivary malondialdehyde levels as a marker of lipid peroxidation in early childhood caries. Eur J Dent. 2018 Jan-Mar; 12(1): 67-70. PMID: 29657527.

[19]. Govindaraju L, Gurunathan D. Effectiveness of Chewable Tooth Brush in Children-A Prospective Clinical Study. J Clin Diagn Res. 2017 Mar; 11(3): ZC31-ZC34. PMID: 28511505.

[20]. Laing E, Ashley P, Naini FB, Gill DS. Space maintenance. International journal of paediatric dentistry. 2009 May; 19(3): 155-62.

[21]. Ramakrishnan M, Bhurki M. Fluoride, Fluoridated Toothpaste Efficacy And Its Safety In Children-Review. International Journal of Pharmaceutical Research. 2018 Oct 1; 10(04): 109-14.

[22]. Somasundaram S, Ravi K, Rajapandian K, Gurunathan D. Fluoride Content of Bottled Drinking Water in Chennai, Tamilnadu. J Clin Diagn Res. 2015 Oct; 9(10): ZC32-4. PMID: 26557612.

[23]. Packiri S, Gurunathan D, Selvarasu K. Management of Paediatric Oral Ranula: A Systematic Review. J Clin Diagn Res. 2017 Sep; 11(9): ZE06-ZE09. PMID: 29207849.

[24]. Christabel SL, Gurunathan D. Prevalence of type of frenal attachment and morphology of frenum in children, Chennai, Tamil Nadu. World J Dent. 2015 Oct; 6(4): 203-7.

[25]. Guelmann M, McEachern M, Turner C. Pulpectomies in primary incisors using three delivery systems: an in vitro study. J Clin Pediatr Dent. 2004 Summer; 28(4): 323-6. PMID: 15366621.

[26]. Melius B, Jiang J, Zhu Q. Measurement of the distance between the minor foramen and the anatomic apex by digital and conventional radiography. J Endod. 2002 Feb; 28(2): 125-6. PMID: 11833685.

[27]. Krishnan IS, Sreedharan S. A comparative evaluation of electronic and radiographic determination of root canal length in primary teeth: An in vitro study. Contemp Clin Dent. 2012 Oct; 3(4): 416-20. PMID: 23633801.

[28]. Katz A, Mass E, Kaufman AY. Electronic apex locator: a useful tool for root canal treatment in the primary dentition. ASDC J Dent Child. 1996 NovDec; 63(6): 414-7. PMID: 9017174.

[29]. Ghaemmaghami S, Eberle J, Duperon D. Evaluation of the Root ZX apex locator in primary teeth. Pediatr Dent. 2008 Nov-Dec; 30(6): 496-8. PMID: 19186775.

[30]. Neena IE, Ananthraj A, Praveen P, Karthik V, Rani P. Comparison of digital radiography and apex locator with the conventional method in root length determination of primary teeth. J Indian Soc Pedod Prev Dent. 2011 OctDec; 29(4): 300-4. PMID: 22016313.

[31]. Saritha S, Uloopi KS, Vinay C, Chandra Sekhar R, Rao VV. Clinical evaluation of Root ZX II electronic apex locator in primary teeth. Eur Arch Paediatr Dent. 2012 Feb; 13(1): 32-5. PMID: 22293103.

[32]. Herrera M, Abalos C, Planas AJ, Llamas R. Influence of apical constriction diameter on Root ZX apex locator precision. J Endod. 2007 Aug; 33(8): 995-8. PMID: 17878091.

[33]. Gordon MP, Love RM, Chandler NP. An evaluation of .06 tapered guttapercha cones for filling of .06 taper prepared curved root canals. Int Endod J. 2005 Feb; 38(2): 87-96. PMID: 15667630. 